\title{
Influence of dl-phenylpropanolamine on brown adipose tissue thermogenesis in the adult rat
}

\author{
PAUL J. WELLMAN \\ Texas A\&M University, College Station, Texas
}

\begin{abstract}
Phenylpropanolamine (PPA) produces weight loss that may result, in part, from an excitatory action of PPA on brown adipose tissue (BAT) thermogenesis. Adult male and female rats were anesthetized with $1.2 \mathrm{~g} / \mathrm{kg}$ urethane and treated (ip) with either $0.9 \%$ saline or $5,10,20$, or $40 \mathrm{mg} / \mathrm{kg}$ dl-PPA. Interscapular BAT (IBAT) and rectal temperatures were recorded every minute for $10 \mathrm{~min}$ prior to and $60 \mathrm{~min}$ following drug injection. Control rats exhibited stable IBAT and rectal temperatures prior to and after saline injection, whereas PPA-treated rats exhibited increases in IBAT temperature and, after a 10-15-min lag, in rectal temperature. There were no differences between male and female rats with regard to the effect of PPA on IBAT and rectal temperature. The implications of these data for an explanation of the weight-reducing effect of PPA are discussed.
\end{abstract}

Phenylpropanolamine (PPA), a phenethylamine, produces anorexia and weight loss (Abdallah, 1968; Griboff, Berman \& Silverman, 1975; Hoebel, 1976; Wellman \& Peters, 1980). The precise explanation for these effects, however, is presently unclear. Hoebel (1976) suggested that the anorexic effect of PPA was the result of an action of this drug on feeding mechanisms within or near the lateral hypothalamus. In contrast, Wellman, Malpas, and Wikler (1981) observed that PPA produced hypodipsia and conditioned taste aversion at dosage levels ( 10 and $20 \mathrm{mg} / \mathrm{kg}$ ) that produce anorexia; these authors suggested that a putative malaise effect of PPA might induce anorexia and weight loss.

Another explanation for the weight-reducing action of PPA may relate to a potential effect of PPA on basal energy metabolism. Body-weight fluctuations can be ascribed to changes in either food intake and absorption and activity (work) or resting metabolism. Ignoring the obligatory thermogenesis that results from food digestion, an important contibuting factor of resting metabolism is the thermogenic activity of brown adipose tissue (BAT). This unique form of adipose tissue liberates heat via uncoupled respiration upon stimulation by beta-adrenergic agonists or by stimulation of the sympathetic nervous system (Flaim Horwitz, \& Horwitz, 1977; Himms-Hagen, 1976). BAT thermogenesis is stimulated when mammals are maintained in cold environs and when mammals overeat calorically dense diets. The former effect, termed nonshivering thermogenesis, serves to maintain core temperature during acute and chronic cold exposure,

This research was supported by a grant (\#32525-1014) from the Thompson Medical Company. Cindi Arms collected a portion of the temperature data, and Michelle Marmon assisted in data entry and analyses. Requests for reprints should be directed to the author at the Department of Psychology, Texas A\&M University, College Station, TX 77843 . whereas the latter effect, termed diet-induced thermogenesis (DIT), serves to waste ingested calories and therefore reduce obesity (Foster \& Frydman, 1978; Rothwell \& Stock, 1979). In contrast, a deranged BAT thermogenic mechanism might contribute to the development of obesity. Indeed, reduced BAT thermogenesis has been observed in several models of obesity, including the ventromedial hypothalamic rat (Seydoux, Rohner-Jeanrenaud, Assimacopoulos, \& Girardier, 1981; Vander Tuig, Knehans, \& Romsos, 1982), the obese ob/ob mouse (Thurlby \& Trayhurn, 1978), and the obese Zucker (fa/fa) rat (Milam, Stern, \& Horwitz, 1982).

Presumably, weight loss might be induced by overstimulation of BAT thermogenesis in mammals. Interestingly, amphetamine, an anorexic agent that reduces food intake and produces weight loss, stimulates BAT thermogenesis (Wellman, 1983). Other sympathomimetic agents, including ephedrine and 4-hydroxyamphetamine, also produce marked BAT thermogenesis (Buckowiecki, Jahjah, \& Follea, 1982; Wellman \& Watkins-Freeman, 1984). These agents, as well as PPA, share a similar stereochemical structure and induce the release of catecholamines from both sympathetic neurons and the adrenal medulla (Axelrod, 1970; Burn \& Rand, 1959; Rubin \& Jaanus, 1966). To evaluate the proposal advanced herein that PPA may induce weight loss, in part via stimulation of BAT thermogenesis, the present experiment examined the effect of dl-PPA $(0,5,10,20$, or 40 $\mathrm{mg} / \mathrm{kg}$, ip) on in vivo interscapular brown adipose tissue (IBAT) and rectal temperature in adult male and female rats.

\section{METHOD}

\author{
Subjects \\ The subjects were 40 adult ( 70 days old) male and female Sprague- \\ Dawley rats (Timco; Houston, Texas). The rats were segregated
}


by sex and double-housed in plastic rodent cages (Lab Products) in a temperature-controlled room $\left(23.0 \pm 0.5^{\circ} \mathrm{C}\right)$ under continuous illumination. The rats were given continuous access to tap water and standard rat pellets (Purina Rat \& Mouse Diet) throughout the experiment.

\section{Drugs}

A saline solution was prepared using $.9 \%$ sodium chloride dissolved into sterile distilled water. PPA solutions $(5,10,20$, and $40 \mathrm{mg} / \mathrm{ml}$ ) were prepared by dissolving dl-PPA into sterile distilled water. dl-PPA (Lot \#3E37) was obtained from the H. Reisman Company. All drug concentrations were calculated as the salt (Seiden \& Dykstra, 1977) and were prepared just prior to injection.

\section{Procedure}

Surgery and temperature measurements were made under anesthesia induced by injection of urethane (Sigma; $1.2 / 10 \mathrm{ml} / \mathrm{kg}$, ip). For each rat, the skin over the shoulders was shaved and a $3-\mathrm{cm}$ longitudinal incision was made over the interscapular region. Each rat was placed on a foam pad suspended over a heat source. A thermoprobe, insulated with silicone (Strawberry Tree, $3 \mathrm{~mm}$ in length and $2 \mathrm{~mm}$ in diameter) was positioned between the major lobes of IBAT, and the skin over IBAT was closed around the thermoprobe cable using hemostats. The tip of a second probe was positioned $4 \mathrm{~cm}$ into the rectum to record core temperature. IBAT and rectal temperatures were recorded every minute to the nearest $0.1^{\circ} \mathrm{C}$ using a micromcomputer (Apple-IIE) outfitted with a dual thermometer card (Strawberry Tree, Inc.).

Basleine temperatures were recorded for a 10 -min period prior to drug injection in a room maintained at $23.0 \pm 0.5^{\circ} \mathrm{C}$. The distance between each rat and the heat source was adjusted to as to maintain rectal temperature between $34^{\circ}$ and $36^{\circ} \mathrm{C}$ during the 10 min period prior to injection. Separate groups of rats $(n=4$ each) of male and female rats were treated (ip) with $0.9 \%$ saline or with one of the dose levels of dl-PPA, and temperatures were recorded for a $60-\mathrm{min}$ period following injection.

\section{Statistical analyses}

The design of this experiment represents a $2 \times 5 \times 8$ split-plot factorial, with sex (male/female) and dose $(0,5,10,20$, and $40 \mathrm{mg} / \mathrm{kg} \mathrm{dl}$-PPA) as the between-group factors, and time (after injection: $-10,0,10,20,30,40,50$, and $60 \mathrm{~min}$ as the withingroup factor. Between- and within-group comparisons were made using a priori two-tailed $t$ tests (Kirk, 1968) after separate factorial ANOVAs of the IBAT and rectal temperature data.

\section{RESULTS}

The effects of dl-PPA on IBAT temperature are depicted in Figure 1. There were no significant differences between the groups with regard to IBAT temperature at $10 \mathrm{~min}$ prior to and at time of injection ( $\mathrm{p}<.32$ and .45 , respectively). Rats treated with $0.9 \%$ saline displayed no significant changes in IBAT temperature over the 60-min postinjection period [comparison between temperature at time 0 and at time 60 min: $\mathrm{t}(35)=.38, \mathrm{p}>.25$ ]. In contrast, rats treated with dl-PPA exhibited increases in IBAT temperature at each dose level. Analyses of variance of these data revealed significant effects of dose $[\mathrm{F}(4,30)=$ $16.5, \mathrm{p}<.0001$ ] and time [after injection: $F(7,210)=$ $112.6, \mathrm{p}<.0001]$ and of the interaction between dose and time $[F(28,270)=8.4, p<.0001]$. Although the factor of sex was significant $[\mathrm{F}(1,30)=13.9, \mathrm{p}<.0001]$, there were no significant interactions between sex and dose, sex and time, or sex, dose, and time. Because there

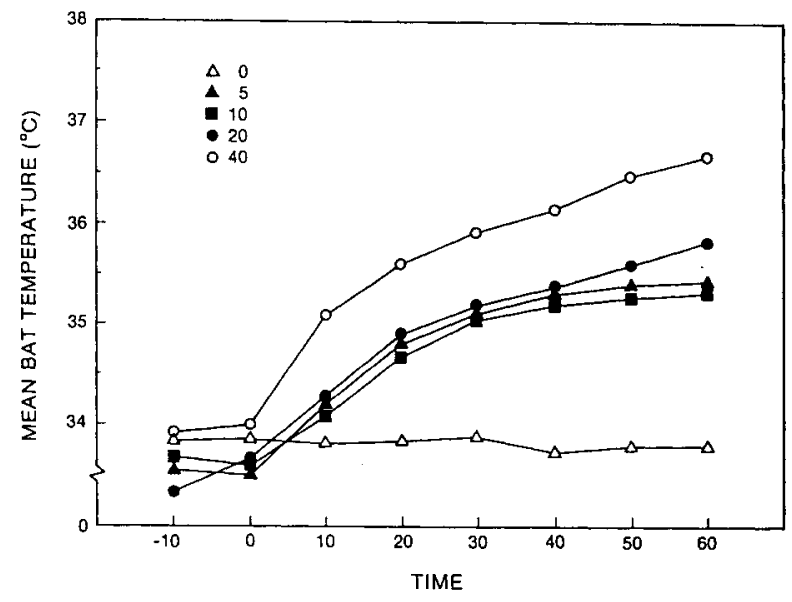

Figure 1. Mean group interscapular brown adipose tissue (IBAT) temperatures plotted at 10 -min intervals prior to, at, and $60 \mathrm{~min}$ after injection with $0.9 \%$ saline $(\triangle), 5 \mathrm{mg} / \mathrm{kg}(\Delta), 10 \mathrm{mg} / \mathrm{kg}(\square)$, $20 \mathrm{mg} / \mathrm{kg}(\bullet)$, or $40 \mathrm{mg} / \mathrm{kg}(\bigcirc)$ dl-PPA.

were no significant interactions between sex and the other variables of interest, subsequent data analyses were computed with combined male and female treatment groups. Rats treated with 5,10 , and $20 \mathrm{mg} / \mathrm{kg}$ dl-PPA exhibited comparable increases in IBAT temperature that were significantly different from the stable temperatures exhibited by the saline-treated rats [Comparison between each dose (collapsed across time) and the saline group: $t(35)=a t$ least $3.36, \mathrm{p}<$ at least .01]. Rats treated with $40 \mathrm{mg} / \mathrm{kg}$ dl-PPA exhibited increases in IBAT temperature that were significantly greater than those of the other PPA treatment groups $[\mathrm{t}(35)=$ at least $3.08, \mathrm{p}<$ at least .01$]$ and the saline-treated group $[\mathrm{t}(35)=6.53, \mathrm{p}<.0001)]$.

Figure 2 depicts the changes in rectal temperature induced by the various doses of dl-PPA in this experiment. Rectal temperatures between the groups were not significantly different prior to injection or at the time of injection. As was the case with IBAT temperature,

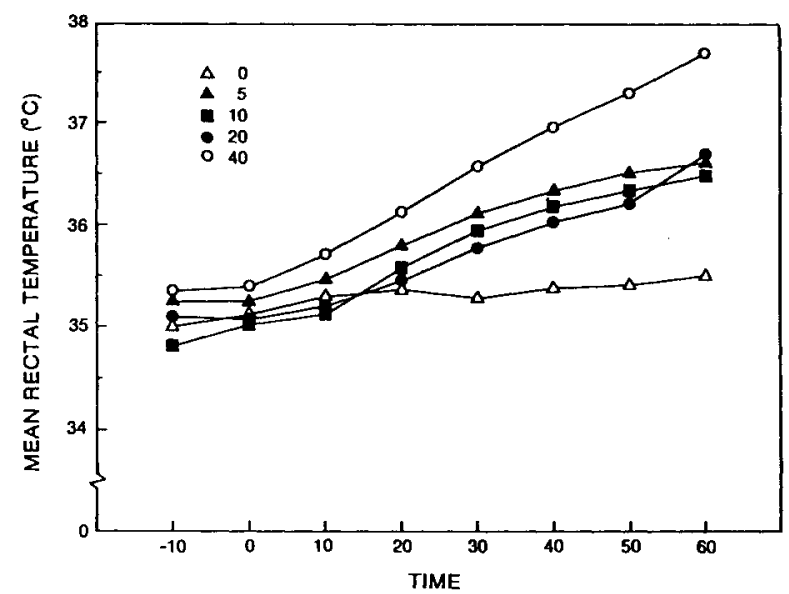

Figure 2. Mean group rectal temperatures plotted at 10-min intervals prior to, at, and $60 \mathrm{~min}$ after injection with $0.9 \%$ saline $(\triangle)$, $5 \mathrm{mg} / \mathrm{kg}(\Delta), 20 \mathrm{mg} / \mathrm{kg}(\bullet)$, or $40 \mathrm{mg} / \mathrm{kg}(\bigcirc)$ dl-PPA. 
saline-treated rats did not exhibit significant changes in rectal temperature across the 60 -min postinjection interval [comparison between temperature at time 0 and time 60 min: $\mathrm{t}(35)=.49, \mathrm{p}<.50]$. Rectal temperature was increased by dl-PPA but lagged behind the increases in IBAT by approximately 5-15 min, depending on the dose. Analyses of variance revealed significant effects of dose $[F(4,35)=5.6, p<.0001]$, of time $[F(7,245)=114.3$, $\mathrm{p}<.0001]$, and of the interaction between dose and time $[\mathrm{F}(28,245)=5.35, \mathrm{p}<.0001]$. Rats treated with 5,10 , or $20 \mathrm{mg} / \mathrm{kg}$ dl-PPA exhibited comparable increases in rectal temperature that were not significantly different from the change in rectal temperature exhibited by the control group. In contrast, rats treated with $40 \mathrm{mg} / \mathrm{kg}$ dlPPA displayed increments in rectal temperature that were significantly greater than those observed in the control group $[\mathrm{t}(35)=3.39, \mathrm{p}<.01]$.

\section{DISCUSSION}

Enhanced IBAT thermogenesis was observed in male and female rats treated with an extended dose range of dl-PPA. In particular, injections of 5,10 , or $20 \mathrm{mg} / \mathrm{kg}$ dl-PPA produced comparable increases in IBAT temperature (approximately $2.0^{\circ} \mathrm{C}$ ) over a 60 -min period after injection. Rats treated with $40 \mathrm{mg} / \mathrm{kg}$ dl-PPA displayed even larger increases in IBAT temperature (approximately $2.8^{\circ} \mathrm{C}$ ). Although IBAT baseline temperatures were significantly lower in female rats, there were no differences between the sexes with regard to the magnitude of the thermogenesis induced by PPA within IBAT. PPA also significantly increased rectal temperature. It seems likely that the increases in rectal temperature are, in part, the result of the thermogenesis induced by PPA within BAT. First, the temperature increases recorded within the rectum always followed, after a time, the increases in IBAT temperature. For example, if one calculates the time required for the change in tissue temperature to reach $50 \%$ of the final temperature, BAT temperature changes preceded the changes in rectal temperature (the time to $50 \%$ for BAT was $25 \mathrm{~min}$ in $40-\mathrm{mg} / \mathrm{kg}$ rats but $40 \mathrm{~min}$ for rectal temperature). Another factor that may contribute to the thermogenic action of PPA is the vasoconstrictive action of PPA that would limit the loss of heat through the skin.

Arch, Ainsworth, and Cawthorne (1982) compared the thermogenic action of several ephedrine congeners and isomers (including dl-PPA) on energy expenditure in mice, using an indirect calorimetry technique. Those authors noted that dl-PPA produced significant anorexia, reduced lipid content, and enhanced energy expenditure in mice. The present data support and extend the findings of Arch et al. (1982) in that rats treated with dl-PPA exhibit marked increments in IBAT temperature and rectal temperature. The present data, however, directly link the thermogenic action of PPA to activation of brown adipose tissue thermogenesia. Other studies from this laboratory have replicated the thermogenic action of di-PPA and have demonstrated a synergism of caffeine on IBAT thermogenesis (Wellman \& Marmon, in press) and found that d-isomer of PPA is half as thermogenic as the l-isomer (Wellman \& Marmon, 1985).

PPA is known to produce anorexia and to reduce both body weight in mice, rats, and humans and body lipid levels (Arch et al., 1982; Griboff et al., 1975; Hoebel, 1976). The present data suggest that the lower lipid levels observed after prolonged PPA treatment may reflect chronic activation of BAT thermogenesis. Activation of BAT is accompanied by both a simultaneous increase in blood flow to BAT and a depletion of venous oxygen levels. Moreover, fuel substrates are mobilized to support enhanced BAT thermogenesis. The thermogenic effect of PPA on IBAT and the concomitant expenditure of lipid and glucose may explain the reduced blood glucose level observed in rats after PPA treatment (Resnick, Hernandez, Chen, \& Hoebel, 1978). Moreover, the effect of PPA on BAT thermogenesis is not a transient activational effect. Tracy L. Sellers (unpublished data, 1985) has demonstrated that chronic treatment of rats with $20 \mathrm{mg} / \mathrm{kg}$ dl-PPA (twice a day) resulted in anorexia, weight loss, and, most importantly, enhanced basal brown adipose tissue thermogenesis.

PPA, as do other sympathomimetic agents, induces the release of catecholamines from sympathetic nerve terminals and from the adrenal medulla. The thermogenic effect of PPA is not the result of adrenal catecholamine release, since adrenal demedulation has no effect on the IBAT thermogenesis, or of the direct stimulation of BAT postsynaptic receptors, since reserpine completely abolishes the thermogenic action of PPA (Wellman \& Marmon, 1985). PPA has been characterized as an alpha agonist, primarily on the basis of its vasoconstrictive property. That PPA induces BAT thermogenesis superficially presents a paradox in that BAT thermogenesis is primarily considered to be a beta-adrenergic phenomenon. Yet, several experiments have demonstrated that the alpha-agonist, phenylephrine, induces moderate BAT thermogenesis (Buckowiecki, Follea, Paradis, \& Collet, 1980; Flaim et al., 1977). Interestingly, Flaim et al. (1977), using an in vivo procedure comparable to that used herein, observed that systematic variation of phenylephrine dosage did not increase the peak thermogenic response of IBAT. In the present experiment, PPA did not induce dose-dependent increases of IBAT temperature within a range of dosages $(5-20 \mathrm{mg} / \mathrm{kg})$ in which the anorexic property of PPA is dose-dependent (Wellman \& Peters, 1980). This result may be partially consistent with an alpha adrenergic explanation, but a final conclusion awaits the assessment of alpha and beta adrenergic blockade on the IBAT thermogenesis induced by PPA.

\section{REFERENCES}

Adballah, A. H. (1968). Anorectic activity of ephedrine isomers. Life Sciences, 7, 665-670.

Arch, J., Ainsworth, A. T., \& Cawthorne, M. A. (1982). Thermogenic and anorectic effects of ephedrine and congeners in mice and rats. Life Sciences, 30, 1817-1836. 
Axelrod, J. (1970). Amphetamine: Metabolism, physiological disposition and its effect on catecholamine storage. In E. Costa \& S. Garratini (Eds.), Amphetamines and related compounds, New York: Raven Press.

Buckowiecki, L., Follea, N., Paradis, A., \& Collet, A. (1980). Stereospecific stimulation of brown adipocyte respiration by catecholamines via B-1 adrenoreceptors. American Journal of Physiology, 238, E552-E563.

Buckowiecki, L., Jahjah, B., \& Follea, N. (1982). Ephedrine, a potential slimming drug, directly stimulates thermogenesis in brown adipocytes via B-adrenoreceptors. International Journal of Obesity, 6, 343-350.

BuRN, J. H., \& RAND, M. J. (1959). Fall of blood pressure after a noradrenaline infusion and its treatment by pressor agents. British Journal of Medicine, 1, 394-397.

Flaim, K. E., Horwitz, B. A., \& Horowitz, J. M. (1977). Coupling of signals to brown fat: Alpha- and beta-adrenergic responses in intact rats. American Journal of Physiology, 232, R101-R109.

Foster, D. O., \& Frydman, M. L. (1978). Nonshivering thermogenesis in the rat. Canadian Journal of Physiology and Pharmacology, 55, $110-122$.

Griboff, S. I., Berman, R., \& Silverman, H. I. (1975). A doubleblind clinical examination of a phenylpropanolamine-caffeine-vitamin combination and a placebo in the treatment of exogenous obesity. Current Therapeutic Research, 17, 535-543.

Himms-Hagen, J. (1976). Cellular thermogenesis. American Review of Physiology, 38, 315-351.

HoEbel, B. G. (1976). Satiety: Hypothalamic stimulation, anorectic drugs, and neurochemical substrates. In D. Novin, W. Wyrwicka, \& G. Bray (Eds.), Hunger: Basic mechanisms and clinical implications. New York: Raven Press.

KIRK, R. J. (1968). Experimental design: Procedures for the behavioral sciences. Belmont, CA: Brooks/Cole.

Milam, K. M., Stern, J. S., \& Horwitz, B. A. (1982). Isoproterenol alters non-shivering thermogenesis in the Zucker obese rat (fa/fa) Pharmacology, Biochemistry and Behavior, 16, 627-630.

Resnick, S. I., Hernandez, L., Chen, J., \& Hoebel, B. G. (1978). Effect of the anorectic drug, phenylpropanolamine, on blood glucose in rats. Pharmacology, 17, 157-162.
RothwelL, N. J., \& STock, M. J. (1979). A role for brown adipose tissue in diet-induced thermogenesis. Nature, 281, 31-35.

RUBin, R. P., \& JAANUS, S. (1966). Release of catecholamines from the adrenal medulla by indirectly acting sympathomimetic amines. Pharmacology and Experimental Pathology, 2, 125-137.

Seiden, L. S., \& Dykstra, L. (1977). Psychopharmacology: A Biochemical and Behavioral Approach. New York: Van Nostrand.

Seydoux, J., Rohner-Jeanrenaud, F., Assimacopoulos, B., \& GIRARDIER, L. (1981). Functional disconnection of brown adipose tissue in hypothalamic obesity in rats. Pflügers Archiv, 390, 1-4.

ThurLBy, P. L., \& Trayhurn, P. (1978). The development of obesity in preweanling ob/ob mice. British Journal of Nutrition, 39, 397-402.

Vander Tuig, J. G., Knehans A. W., \& Romsos, D. R. (1982). Reduced sympathetic nervous system activity in rats with ventromedial hypothalamic lesions. Life Sciences, 30, 913-920.

WeLlMAN, P. J. (1983). Influence of amphetamine on brown adipose tissue thermogenesis. Research Communications in Clinical Pathology and Pharmacology, 41, 173-176.

Wellman, P. J., Malpas, P. B., \& Wikler, K. C. (1981). Conditioned taste aversion and unconditioned suppression of water intake induced by phenylpropanolamine in rats. Physiological Psychology, 9, 203-207.

Wellman, P. J., \& Marmon, M. (1985). Comparison of phenethylamine congeners and isomers on brown adipose tissue thermogenesis. Unpublished manuscript.

Wellman, P. J., \& Marmon, M. (in press). Synergism between caffeine and dl-phenylpropanolamine on brown adipose tissue thermogenesis in the adult rat. Pharmacology, Biochemistry \& Behavior.

Wellman, P. J., \& Peters, R. H. (1980). Influence of amphetamine and phenylpropanolamine on food intake in rats with ventromedial hypothalamic or dorsolateral tegmental damage. Physiology \& Behavior, 25, 819-827.

Welliman, P. J., \& Watkins-Freeman, P. A. (1984). Influence of 4 hydroxyamphetamine on in vivo brown adipose tissue thermogenesis and feeding behavior in the rat. Behavioral Neuroscience, 98 , 1060-1064.

(Manuscript received July 19, 1984; revision accepted for publication January, 1 1985.) 